\title{
COMPARATIVE TEST OF HEART RATE EVOLUTION BETWEEN TWO GROUPS OF UNTRAINED MEN AND WOMEN
}

\author{
Mihai-Cosmin CIOCÎRLAN ${ }^{*}$ \\ ${ }^{1}$ National University of Physical Education and Sport, Faculty of Physical Education and Sport, \\ Bucharest, Romania \\ *Corresponding author: cosminktmihai@gmail.com
}

https://doi.org/10.35189/dpeskj.2020.59.4.12

\begin{abstract}
We developed a fitness assessment test battery to help evaluate individual performance in untrained individuals. In the current paper, we will discuss how the heart rate has evolved in two groups of men and women over a period of 120 days, during which the subjects followed a standardised training protocol. For our research, we monitored the heart rate of each subject during a standardised treadmill test. We used a test that we developed especially for untrained individuals, which required them to walk on a treadmill with a $15 \%$ incline for 10 minutes, at a constant speed of $5 \mathrm{~km} / \mathrm{h}$. We tested the subjects on days 1,60 and 120. After conducting our experiment, we found a decrease in resting heart rate of 6.4 beats per minute in men and 3.4 beats per minute in women. Exercise heart rate recorded a drop of 9.4 beats per minute in the male group and 8.8 beats per minute in the female group throughout the 120 days of the training programme. We noted that the group of men recorded a greater improvement in resting heart rate than the group of women, with a difference of $4.84 \%$, while exercise heart rate had almost similar values, with a difference of only $0.03 \%$ between the two groups at the end of the 120 days of the test period.
\end{abstract}

Keywords: fitness test, resting heart rate, exercise heart rate.

\section{Introduction}

Today, we live in a society where human motor skills are increasingly put in the background (Tremblay et al., 2010) largely due to technological advances, which places people in the position of no longer needing to use their physical energy to meet their daily needs and tasks. This translates into a narrowing of the time the locomotor system is used, which contributes to a regression of its function (Jebb \& Moore, 1999; Myers et al., 2004).

Based on the fact that more and more people become sedentary, as Troiano et al. (2008) pointed out, we believe that now it is more important than ever to focus on physical activities, given the positive results they bring to an individual's physical, mental and social status. This motivates us to search for ways to involve sedentary people in physical activities.

The ultimate goal for us is to help reduce the number of people who end up being affected by health problems caused by the lack of movement of the human body.

In this respect, we aim to develop methods and means to make the impact of exercise programmes more efficient on the fitness components, firstly to increase the performance of a workout and secondly to allow sedentary people to easily integrate into exercise programmes.

We decided to focus our study on the heart function due to the fact that the heart represents the most important muscle of the human body. Hillman et al. (2008), Cambell et al. (2001) and Hiilloskorpi et al. (2003) suggest through their findings that, as long as we can keep the heart healthy, we will influence the functionality of other organs, which will be improved. The effects can go as far as improving the mental aspects of an individual. 
Reimers et al. (2018) pointed out, during an extensive systematic review and metaanalysis of interventional studies, that resting heart rate can be positively influenced by physical activities, regardless of their intensity and duration. Even light activities such as yoga and stretching sessions have been shown to have a positive impact on the resting heart rate of an individual. This is good news for the sedentary population that we aim to help, because we can think in a new way about the role that the fitness industry plays in our daily lives. Instead of looking at the best performers that the fitness industry has to offer, we can look at how we can apply the best training principles and methods in order to train sedentary people as little as possible, as seldom as possible, and yet manage to obtain positive results for the cardiovascular system.

Hillman et al. (2008) show that there is a correlation between an individual's resting heart rate and expected lifespan. The normal range for resting heart rate covers values between 60 beats per minute and 100 beats per minute. When taking into account that we usually have the same maximum heart rate of around 180-190 beats per minute, the lower the resting heart rate, the wider the range of exercise that the cardiovascular system can withstand (Tanaka et al., 2001). These facts suggest that, if we can reduce the resting heart rate of a healthy individual, we can increase their general health status and quality of life in the long term.

The second aspect of great interest to us was the relationship between heart rate and blood pressure. More specifically, what evidence suggests the impact of heart rate on blood pressure and not vice versa. Although we could not find any significant data on this matter, we found that studies on this topic were mainly focused on the correlation between resting heart rate and general health, as shown by Ferrières and Ruidavets (1999).

Physical exercise is one of the most important means of action to improve health status. Rexhepi and Brestovci (2014) point out the relationship between VO2max and the resting heart rate of an individual, which is a direct correlation between aerobic capacity and how easy it is for the heart to sustain the homeostatic status of the body. By correlating VO2max with musculoskeletal fitness and health, Warburton et al. (2001) highlight the importance of physical exercise in our daily lives.

The objective of our research was to compare how a 120-day training programme influenced the parameters of the cardiovascular system in a group of men and women aged 30 to 40 years. We were interested in resting heart rate and exercise heart rate during a standardised assessment protocol.

\section{Methodology}

In our study, we used the following research methods:

- Observation - the observation method was used to extract information about the effects that conventional exercise programmes in fitness centres have on participants. That is why we applied the following: systematic observation, through which we monitored a series of parameters and the results obtained by the subjects, like resting heart rate and exercise heart rate; continuous observation, through which we monitored the evolution of the subjects and how they got involved in the training schedules. 
- Statistical and mathematical method - for the statistical relevance of our data, we used the non-parametric Wilcoxon test to analyse the significance between the first and second test for our subjects and the non-parametric Friedman test for repeated measures to analyse the data between the first, second and last test of our subjects. We decided to use non-parametric tests because the collected data did not follow the normal distribution pattern. A standard p-value of 0.05 was used for our level of significance.

- Graphical and tabular methods - were used to highlight the obtained results. Graphical representations were made with the Microsoft Office program.

\section{Participants}

The subjects included in the research are 23 adults who carry out relatively static professional activities and sometimes get involved in physical activities. Age: between 30 and 40 years, 8 men and 15 women.

\section{Measures}

The heart rate of our research subjects was recorded with the digital heart rate monitor of the Life Fitness Integrity Series Treadmill.

\section{Procedure}

The research took place at the Orhideea Spa fitness centre over a period of 120 days. The facility was well equipped to carry out the testing phase of our research and also the training.

We tested each subject at the beginning, after 60 days and after 120 days of training.

The subjects followed a well-designed training routine throughout the research and were constantly supervised by a personal trainer to ensure the safe implementation of all training protocols and that the participants performed the desired exercises with the correct working technique.

For the classification of our results, we used the test scale found in Table 1. Aerobic capacity assessment is a test that we developed to test heart rate fluctuations during aerobic exercise for untrained individuals.

Table 1. Aerobic capacity assessment

\begin{tabular}{|c|c|c|c|c|c|}
\hline \multicolumn{6}{|c|}{$\begin{array}{l}\text { Treadmill walk - } 5 \mathrm{~km} / \mathrm{h}, 15 \% \text { incline for } 10 \text { minutes } \\
\text { Average heart rate }\end{array}$} \\
\hline Result & $\begin{array}{l}\text { Very bad } \\
200 / 180\end{array}$ & $\begin{array}{c}\mathrm{Bad} \\
170 / 160\end{array}$ & $\begin{array}{c}\text { Good } \\
150 / 140\end{array}$ & $\begin{array}{l}\text { Very good } \\
130 / 125\end{array}$ & $\begin{array}{c}\text { Excellent } \\
115 / 110\end{array}$ \\
\hline
\end{tabular}

The aerobic capacity test required the subjects to walk for 10 minutes on a treadmill with a $15 \%$ incline at a constant speed of $5 \mathrm{~km} / \mathrm{h}$. We monitored their heart rate at all times and recorded their average heart rate for the test. 
The aerobic capacity assessment scale is a test that we built for our $\mathrm{PhD}$ thesis, as part of a comprehensive fitness assessment scale, with the purpose of monitoring and assessing how the heart rate is influenced by a constant and moderate exercise over a period of 10 minutes.

In order to perform the test, each subject had to walk on the treadmill for 10 minutes at a constant pace of $5 \mathrm{~km} / \mathrm{h}$, with both hands placed on the heart rate sensors. After stepping on the treadmill, the supervisor will first set the treadmill incline at $15 \%$, then set the speed at 5 $\mathrm{km} / \mathrm{h}$. The supervisor will monitor the subject's progress during the test. At the end of the 10 minutes, the supervisor will pause the treadmill and record the average heart rate values.

The results recorded during the test will then be grouped into one of the 5 categories: very bad, bad, good, very good, excellent, and the individual will be given a score from 1 to 10, as follows: for heart rate values over 190 beats per minute, 1 point; 180 beats per minute to 189 beats per minute, 2 points; 170 beats per minute to 179 beats per minute, 3 points; 160 beats per minute to 169 beats per minute, 4 points; 150 beats per minute to 159 beats per minute, 5 points; 140 beats per minute to 149 beats per minute, 6 points; 130 beats per minute to 139 beats per minute, 7 points; 125 beats per minute to 130 beats per minute, 8 points; 115 beats per minute to 124 beats per minute, 9 points; under 115 beats per minute, 10 points.

The two training groups performed workouts that aimed to keep their bodies active while providing low effort, with a minimum frequency of two days per week. We were interested in seeing how the subjects reacted over a long period of time, in our case, 120 days. We consider this approach to be very useful in showing evidence that individual VO2max levels improve, as shown by Uth et al. (2004).

The subjects were constantly supervised by a personal trainer who ensured that all participants in our study performed technically correct exercises and followed the strictly planned training schedule, as shown in Table 2.

Table 2. Workout schedule

\begin{tabular}{|c|c|c|c|c|c|c|c|}
\hline Week 1 & Activity & Week 2 & Activity & Week 3 & Activity & Week 4 & Activity \\
\hline Day 1 & A1 & & A1 & & A1 & & A1 \\
\hline Day 2 & Rest & & Rest & & Rest & & Rest \\
\hline Day 3 & Rest & & Rest & & Rest & & Rest \\
\hline Day 4 & A2 & & A2 & & A2 & & A2 \\
\hline Day 5 & Rest & & Rest & & Rest & & Rest \\
\hline Day 6 & Rest & & Rest & & Rest & & Rest \\
\hline Day 7 & Rest & & Rest & & Rest & & Rest \\
\hline
\end{tabular}

Table 3. Workout plan no. 1

\begin{tabular}{lcccc}
\hline \multicolumn{1}{c}{ Exercise } & Sets & Reps & Rest & Weight \\
\hline Rowing & 2 & 5 minutes & 1 minute & 10 \\
Squats & 3 & 10 & 2 minutes & free weight \\
Deadlifts & 3 & 10 & 2 minutes & $10 \mathrm{~kg}$ \\
Push ups & 3 & 10 & 2 minutes & free weight \\
Back extensions & 3 & 10 & 2 minutes & free weight \\
TRX pull ups & 3 & 10 & 2 minutes & free weight \\
Crunches & 3 & 10 & 2 minutes & free weight \\
\hline
\end{tabular}


The subjects were given two workout plans that included the following exercises: rowing at the Concept 2 ergometer, squats, deadlifts, push ups, back extensions, pull ups at the TRX cable and crunches (Tables 3 and 4).

Participants were taught by the trainers how to perform the exercises in the first sessions in order to limit the risk of injury.

We decided to use the workout plans after reviewing the findings of McArdle et al. (2000), Davis et al. (2000), Winch (2004), Shephard and Shek (1998). The general intensity that we required our participants to attain during the workouts was decided after reviewing the research paper of Yasida et al. (2009).

Table 4. Workout plan no. 2

\begin{tabular}{lcccc}
\hline \multicolumn{1}{c}{ Exercise } & Sets & Reps & Rest & Weight \\
\hline Rowing & 3 & 5 minutes & 1 minute & 10 \\
Squats & 4 & 12 & 2 minutes & $20 \mathrm{~kg}$ \\
Deadlifts & 4 & 12 & 2 minutes & $20 \mathrm{~kg}$ \\
Push ups & 4 & Max rep & 2 minutes & free weight \\
Back extensions & 4 & 20 & 2 minutes & free weight \\
TRX pull ups & 4 & Max rep & 2 minutes & free weight \\
Crunches & 4 & 20 & 2 minutes & free weight \\
\hline
\end{tabular}

\section{Results}

For our study, we gathered the following results, as shown in Tables 5-7 (for women) and 8-10 (for men).

Table 5. Women's group data

\begin{tabular}{lcccccccc}
\hline Name & Age & $\begin{array}{c}\text { Height } \\
(\mathrm{cm})\end{array}$ & $\begin{array}{c}\text { Resting } \\
\text { HR 1 }\end{array}$ & $\begin{array}{c}\text { Resting } \\
\text { HR 2 }\end{array}$ & $\begin{array}{c}\text { Resting } \\
\text { HR 3 }\end{array}$ & Test 1 & Test 2 & Test 3 \\
\hline A.A. & 33 & 155 & 66 & 64 & 64 & 139 & 135 & 133 \\
C.O. & 37 & 175 & 86 & 85 & 84 & 143 & 138 & 136 \\
E.A. & 37 & 169 & 69 & 67 & 66 & 146 & 138 & 138 \\
E.B. & 40 & 160 & 67 & 68 & 66 & 142 & 129 & 130 \\
F.A. & 33 & 162 & 69 & 65 & 67 & 141 & 140 & 139 \\
F.I. & 37 & 157 & 86 & 81 & 76 & 166 & 154 & 151 \\
I.G. & 37 & 167 & 57 & 56 & 57 & 144 & 139 & 127 \\
I.H. & 32 & 164 & 76 & 74 & 72 & 171 & 164 & 163 \\
L.G. & 36 & 169 & 78 & 74 & 76 & 134 & 130 & 128 \\
M.C. & 35 & 165 & 70 & 71 & 67 & 151 & 145 & 138 \\
M.I. & 40 & 171 & 65 & 65 & 63 & 143 & 131 & 135 \\
O.B. & 37 & 174 & 78 & 75 & 73 & 142 & 140 & 140 \\
P.G. & 33 & 158 & 87 & 83 & 79 & 145 & 143 & 142 \\
U.R. & 33 & 168 & 85 & 83 & 81 & 134 & 132 & 127 \\
V.G. & 34 & 166 & 56 & 55 & 53 & 146 & 135 & 128 \\
\hline & & & & & & & &
\end{tabular}


Table 6. Resting heart rate for women

\begin{tabular}{|c|c|c|c|}
\hline & Resting HR I & Resting HR II & Resting HR III \\
\hline Mean & 73.00 & 71.07 & 69.60 \\
\hline Coefficient of variation & 10.25 & 9.43 & 8.76 \\
\hline Median & 70.00 & 71.00 & 67.00 \\
\hline Average difference between 1 and 2 & & 1.9 & \\
\hline Average difference between 1 and 3 & & & 3.4 \\
\hline Percentage variation & & $2.72 \%$ & $4.89 \%$ \\
\hline Wilcoxon test result & \multicolumn{3}{|c|}{ The result is significant at $\mathrm{p}<.01$} \\
\hline W-value & \multicolumn{3}{|c|}{6} \\
\hline Z-value & \multicolumn{3}{|c|}{-3} \\
\hline Sample size & \multicolumn{3}{|c|}{14} \\
\hline P-value & \multicolumn{3}{|c|}{0.0035} \\
\hline Friedman test result & \multicolumn{3}{|c|}{ The result is significant at $\mathrm{p}<.05$} \\
\hline P-value & \multicolumn{3}{|c|}{0.00014} \\
\hline
\end{tabular}

For the "resting heart rate" parameter, we recorded an average of 73.00, 71.07 and 69.60 beats per minute, respectively for measurements I, II and III.

For the Wilcoxon test, the result is significant, with $\mathrm{p}<0.05$. This translates into the fact that the resting heart rate of the subjects has shown a significant variation. Between testing I and II, there was a decrease of 1.9 beats per minute, i.e. a decrease of $2.72 \%$ in the average resting heart rate.

For the Friedman test, the result is significant, with $\mathrm{p}<0.05$. This translates into the fact that resting heart rate has experienced a significant variation from the initial test. Between testing I and III, we recorded a difference of 3.4 beats per minute, i.e. a decrease of $4.89 \%$ in the average resting heart rate.

Table 7. Exercise heart rate statistics for the women's group

\begin{tabular}{|c|c|c|c|}
\hline Parameter & Test 1 & Test 2 & Test 3 \\
\hline Mean & 145.80 & 139.53 & 137.00 \\
\hline Coefficient of variation & 10.23 & 9.36 & 9.80 \\
\hline Median & 143.00 & 138.00 & 136.00 \\
\hline Average difference between 1 and 2 & \multicolumn{3}{|c|}{6.3} \\
\hline Average difference between 1 and 3 & & & 8.8 \\
\hline Percentage variation & & $4.49 \%$ & $6.42 \%$ \\
\hline Wilcoxon test result & \multicolumn{3}{|c|}{ The result is significant at $\mathrm{p}<.05$} \\
\hline $\mathrm{W}$-value & \multicolumn{3}{|c|}{0} \\
\hline Z-value & \multicolumn{3}{|c|}{-3.40} \\
\hline Sample size & \multicolumn{3}{|c|}{15} \\
\hline P-value & \multicolumn{3}{|c|}{0.00064} \\
\hline Friedman test result & \multicolumn{3}{|c|}{ The result is significant at $\mathrm{p}<.05$} \\
\hline P-value & \multicolumn{3}{|c|}{$<.00001$} \\
\hline
\end{tabular}

For the women's group, we recorded an average heart rate of 145.8 beats per minute during the first test, 139.53 beats per minute during the second test and 137 beats per minute during the third test. Speaking in absolute terms, we found a difference of 6.3 beats per minute, meaning 4.49\%, between averages 1 and 2, and a difference of 8.3 beats per minute, meaning $6.42 \%$, between averages 1 and 3 . The difference between averages 2 and 3 was 2.5 beats per minute. 
Our coefficient of variation was 10.23 for the first test, 9.36 for the second test and 9.80 for the third test.

The Wilcoxon test result for the data between test 1 and 2 was significant at $\mathrm{p}<0.05$, with a p-value of 0.00064 , meaning that the recorded results are significant.

The Friedman test result for the data between test 1,2 and 3 was significant at $p<0.05$, with a p-value $<.00001$.

When we correlated the data between resting heart rate and exercise heart rate for the three tests performed, we noticed the following aspects:

- For the first test, the women's group had an average difference between resting heart rate and exercise heart rate of 72.8 beats per minute, meaning that exercise heart rate was $199.7 \%$ of resting heart rate.

- For the second test, the women's group had an average difference between resting heart rate and exercise heart rate of 68.46 beats per minute, meaning that exercise heart rate was $196.3 \%$ of resting heart rate.

- For the third test, the women's group had an average difference between resting heart rate and exercise heart rate of 67.4 beats per minute, meaning that exercise heart rate was $196.8 \%$ of resting heart rate.

When comparing the differences between the first test and the second test, we found a decrease of $2.72 \%$ in resting heart rate and a decrease of $4.49 \%$ in exercise heart rate, meaning a drop of 1.9 beats per minute at rest and 3.4 beats per minute during exercise.

When comparing the differences between the first test and the third test, we found a decrease of $4.49 \%$ in resting heart rate and a decrease of $6.42 \%$ in exercise heart rate, meaning a drop of 6.3 beats per minute at rest and 8.8 beats per minute during exercise.

Table 8. Men's group data

\begin{tabular}{lcccccccc}
\hline Name & Age & $\begin{array}{c}\text { Height } \\
(\mathrm{cm})\end{array}$ & $\begin{array}{c}\text { Resting } \\
\text { HR 1 }\end{array}$ & $\begin{array}{c}\text { Resting } \\
\text { HR 2 }\end{array}$ & $\begin{array}{c}\text { Resting } \\
\text { HR 3 }\end{array}$ & Test 1 & Test 2 & Test 3 \\
\hline D.F. & 36 & 176 & 77.0 & 74.0 & 72.0 & 176.0 & 173.0 & 171.0 \\
F.M. & 40 & 177 & 62.0 & 61.0 & 59.0 & 140.0 & 132.0 & 129.0 \\
G.G. & 38 & 189 & 89.0 & 83.0 & 71.0 & 151.0 & 146.0 & 142.0 \\
G.S. & 39 & 184 & 86.0 & 82.0 & 79.0 & 172.0 & 166.0 & 162.0 \\
I.C. & 33 & 188 & 65.0 & 63.0 & 61.0 & 151.0 & 144.0 & 141.0 \\
P.A. & 36 & 177 & 64.0 & 64.0 & 61.0 & 137.0 & 131.0 & 129.0 \\
R.H. & 34 & 175 & 66.0 & 62.0 & 58.0 & 166.0 & 158.0 & 155.0 \\
U.T. & 31 & 175 & 66.0 & 64.0 & 63.0 & 144.0 & 137.0 & 133.0 \\
\hline
\end{tabular}


Table 9. Resting heart rate for men

\begin{tabular}{lccc}
\hline \multicolumn{1}{c}{ Parameter } & Resting HR I & Resting HR II & Resting HR III \\
\hline Mean & 71.88 & 69.13 & 65.50 \\
Coefficient of variation & 10.66 & 9.17 & 7.56 \\
Median & 66.00 & 64.00 & 62.00 \\
Average difference between 1 and 2 & & 2.8 & \\
Average difference between 1 and 3 & & $3.98 \%$ & $9.73 \%$ \\
Percentage variation & The result is significant at p <.05 \\
Wilcoxon test result & & \\
W-value: 0 & & \\
Z-value: -2.3664 & & \\
Sample size (N): 7 & & \\
P-value: 0.00096 & The result is significant at $\mathrm{p}<.05$ & \\
Friedman test result & & \\
P-value: 0.00054 & & & \\
\end{tabular}

For the "resting heart rate" parameter, we recorded an average of 71.88, 69.13 and 65.50 beats per minute, respectively for measurements I, II and III.

For the Wilcoxon test, the result is significant, with $\mathrm{p}<0.05$. This translates into the fact that the resting heart rate of the subjects has shown a significant variation from the reference value. Between testing I and II, there was a decrease of 2.8 beats per minute, i.e. a decrease of $3.98 \%$ in the average resting heart rate.

For the Friedman test, the result is significant, with $\mathrm{p}<0.05$. This translates into the fact that resting heart rate has experienced a significant variation from the initial test. Between testing I and III, we recorded a difference between averages of 6.4 beats per minute, i.e. a decrease of $9.73 \%$ in the average resting heart rate.

Table 10. Exercise heart rate statistics for the men's group

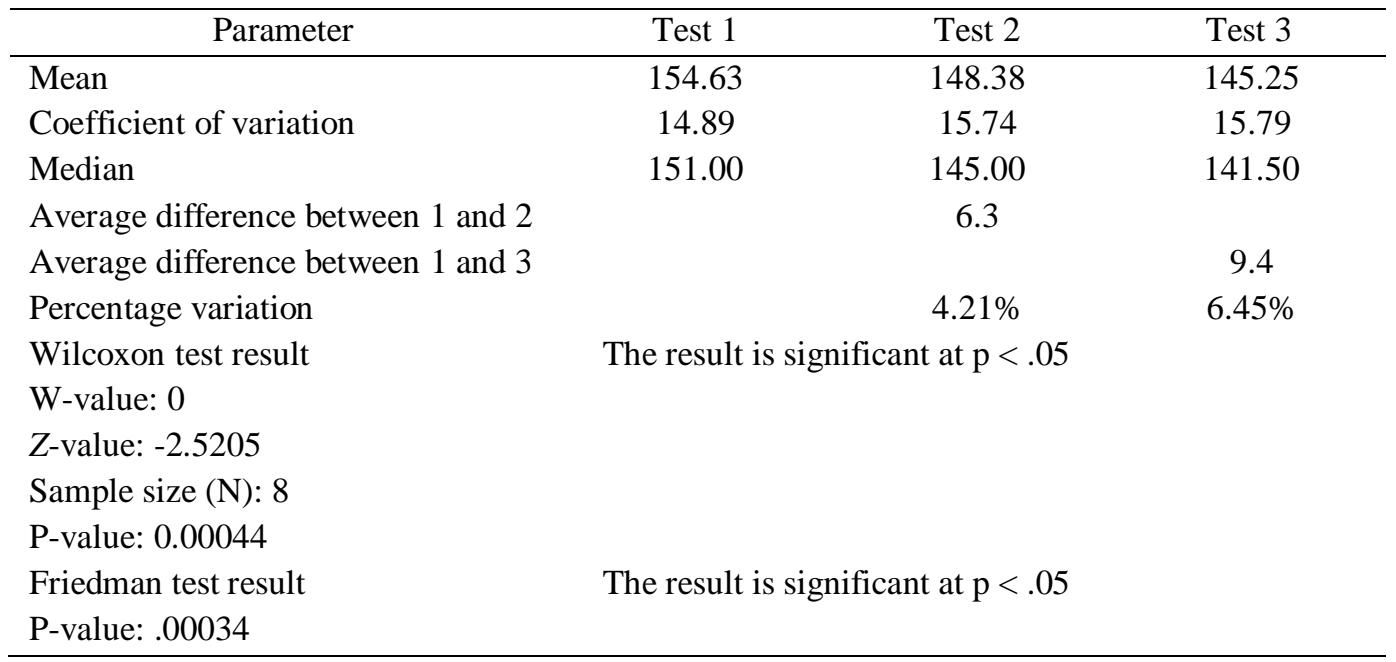

For the men's group, we recorded an average heart rate of 154.63 beats per minute during the first test, 148.38 beats per minute during the second test and 145.25 beats per minute during the third test. Speaking in absolute terms, we found a difference of 6.3 beats per minute between averages 1 and 2, meaning 4.1\%, and a difference of 9.4 beats per minute 
between averages 1 and 3, meaning $6.45 \%$. The difference between averages 2 and 3 was 3.1 beats per minute.

Our coefficient of variation was 14.89 for the first test, 15.74 for the second test and 15.79 for the third test.

The Wilcoxon test result for the data between test 1 and 2 was significant at $p<0.05$, with a p-value of 0.00044 , meaning that the recorded results were significant.

The Friedman test result for the data between test 1, 2 and 3 was significant at $p<.05$, with a p-value of 0.00034 .

When we correlated the data between resting heart rate and exercise heart rate of for the three tests performed, we noticed the following aspects:

- For the first test, the men's group had an average difference of 82.12 beats per minute between resting heart rate and exercise heart rate, meaning that exercise heart rate was $215.12 \%$ of resting heart rate.

- For the second test, the men's group had an average difference of 78.87 beats per minute between resting heart rate and exercise heart rate, meaning that exercise heart rate was $214.6 \%$ of resting heart rate.

- For the third test, the men's group had an average difference of 76.75 beats per minute between resting heart rate and exercise heart rate, meaning that exercise heart rate was $221.75 \%$ of resting heart rate.

When comparing the differences between the first test and the second test, we found a decrease of $3.98 \%$ in resting heart rate and a decrease of $4.21 \%$ in exercise heart rate, meaning a drop of 2.8 beats per minute at rest and 6.3 beats per minute during exercise.

When comparing the differences between the first test and the third test, we found a decrease of $9.73 \%$ in resting heart rate and a decrease of $6.45 \%$ in exercise heart rate, meaning a drop of 6.4 beats per minute at rest and 9.4 beats per minute during exercise.

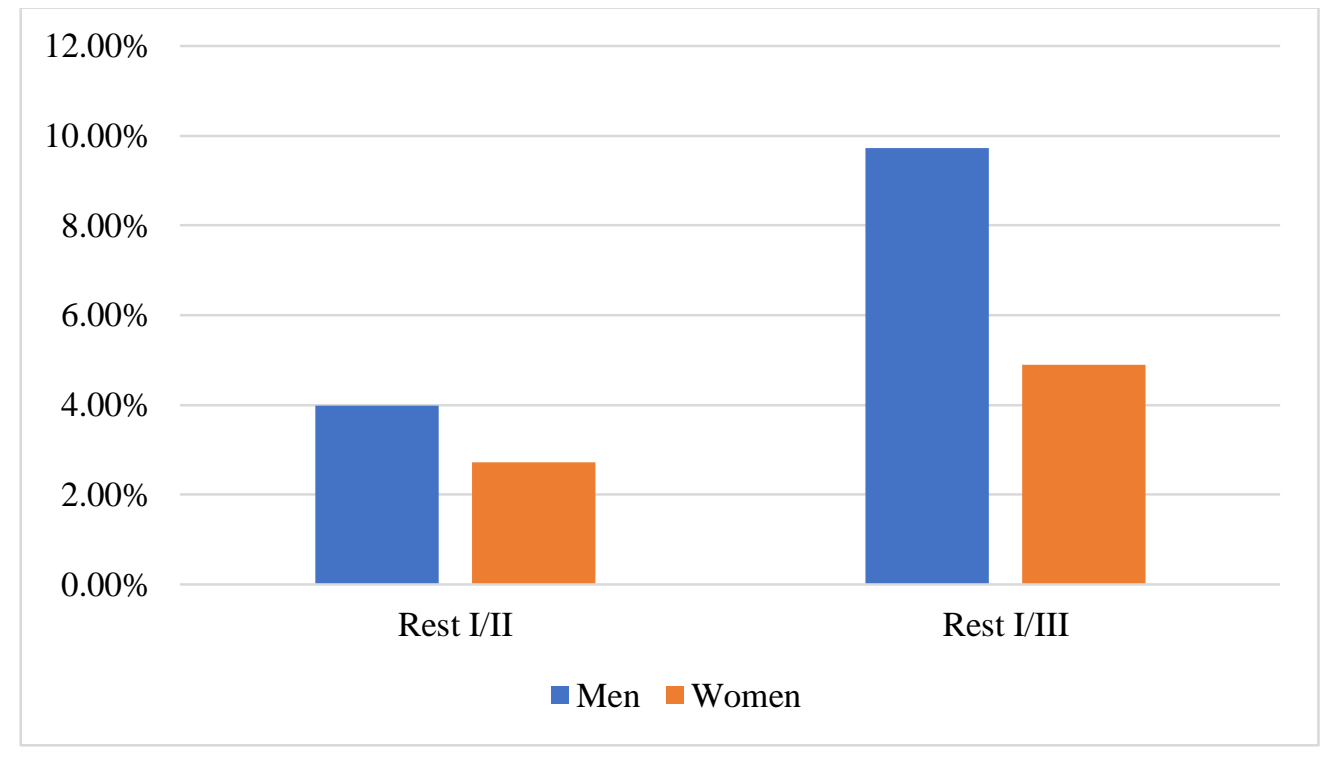

Figure 1. Comparison of resting heart rate between the groups of men and women 
The resting heart rate evolution between the first and second test (Figure 1) recorded a drop of $3.89 \%$ for the male group and a drop of $2.72 \%$ for the female group. We can see a slightly better result (with $1.17 \%$ ) for the group of men.

The resting heart rate evolution between the first and third test (Figure 1) recorded a drop of $9.73 \%$ for the male group and a drop of $4.89 \%$ for the female group. We can see a slightly better result (with $4.84 \%$ ) for the group of men.

The resting heart rate evolution between the second and third test (Figure 1) shows a $3.98 \%$ drop for the male group and a drop of $2.17 \%$ for the female group. We see that the group of men performed slightly better than the group of women, with a difference of $1.81 \%$.

We can say that, for the "resting heart rate" parameter, the men's group recorded a $1.17 \%$ better result than the women's group between the first and second test, and also between the second and third test, with a difference of $3.98 \%$. When comparing the overall evolution, we found that the men's group performed better than the women's group, with a difference of $4.84 \%$.

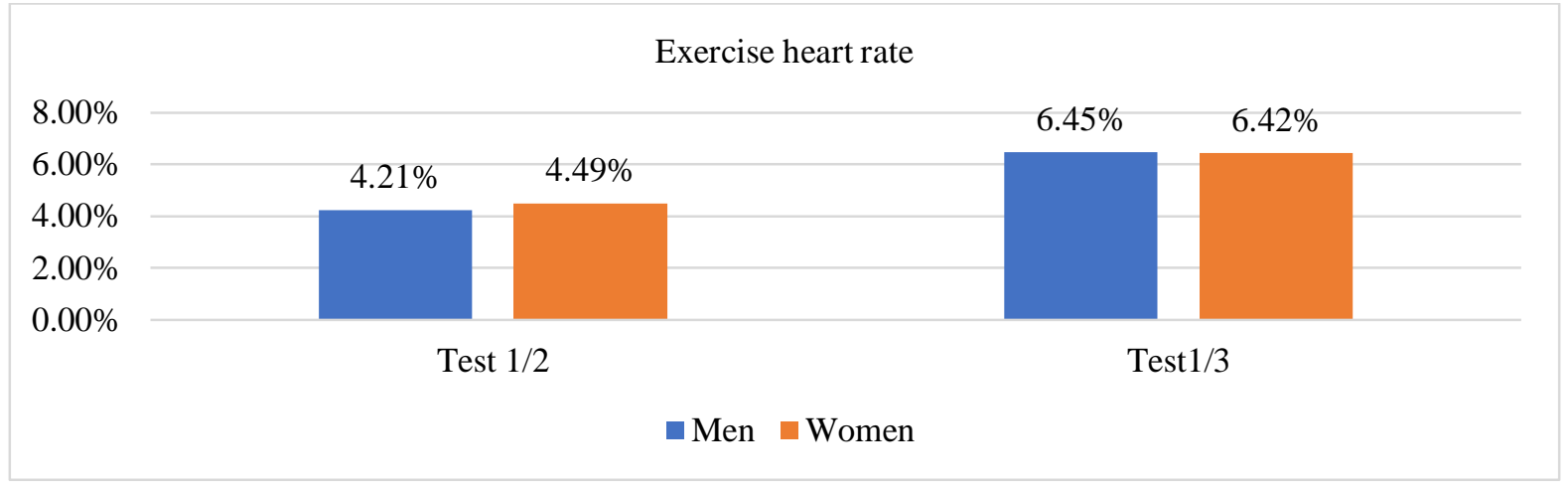

Figure 2. Percentage values of exercise heart rate

The heart rate evolution between the first and second test (Figure 2) recorded a drop of $4.21 \%$ for the male group and a drop of $4.49 \%$ for the female group. We can see a slightly better result (with $0.28 \%$ ) for the group of women, but we can say that the results were similar.

The heart rate evolution between the first and third test (Figure 2) recorded a drop of $6.45 \%$ for the male group and a drop of $6.42 \%$ for the female group. We can see a slightly better result (with $0.03 \%$ ) for the group of men, but we can say that the results were similar.

The heart rate evolution between the second and third test (Figure 2) shows a 2.24\% drop for the male group and a drop of $1.93 \%$ for the female group. We see that the group of men performed slightly better than the group of women, with a difference of $0.31 \%$.

We can say that, for the "exercise heart rate" parameter, the women's group recorded a $0.28 \%$ better result than the men's group between the first and second test. Between the second and third test, the men's group performed slightly better than the women's group, with a difference of $0.31 \%$. When comparing the overall evolution, we found that the men's group performed better than the women's, group with a difference of $0.03 \%$. 


\section{Conclusion}

As our data suggest, physical activity plays a huge role in improving the physical health of an individual, even if the workload is relatively light and the training density is low. We found that the heart rate responded well to a general training stimulus with our test subjects.

Improving heart function is, from our point of view, one of the fundamental objectives of fitness training. Doing this, we can improve the function of the whole human body because the system that delivers oxygen and nutrients to muscles and organs is also improved.

After performing our study, we can definitely say that physical activity has a huge impact on the fitness performance of an untrained individual. Given that we can change the physiology of the body through training, we have a great opportunity to develop healthy habits that can significantly improve an individual's lifestyle. This is why we recommend the implementation of three physical activity sessions in schools and work schedules.

We can say that our test subjects achieved similar results during the 120-day training programme, showing that regular physical activity is very good for the heart. This indicates that physical training triggers similar adaptations in both genders when talking about the exercise adaptation of the cardiovascular system.

We found that the group of men recorded a greater improvement in resting heart rate than the group of women, with a difference of $4.84 \%$, while exercise heart rate had almost similar values, with a difference of only $0.03 \%$ between the two groups at the end of the 120 days of the test period.

Because men have recorded better resting heart rate values during the test, we can say that they can have greater health benefits than women when referring to cardiovascular health in the first phases of physical training. Due to the low number of participants involved in the study, our findings are still subject to measurement errors. For more accurate results, we need to continue our study and apply the tests to a larger group.

We believe that such results can have a wider range of benefits to individual health, given that heart rate is highly correlated with the general level of fitness and health.

\section{References}

Cambell, P. T., Katzmarzyk, P. T., Malina, R. M., Rao, D. C., Pérusse, L., \& Bouchard, C. (2001). Prediction of physical activity and physical work capacity (PWC150) in young adulthood from childhood and adolescence with consideration of parental measures. American Journal of Human Biology, 13(2), 190-196. https://doi.org/10.1002/1520-6300(200102/03)13:2\%3C190::aid-ajhb1028\%3E3.0.co;2-n

Davis, B., Bull, R., Roscoe, J., \& Roscoe, D. (2000). Physical education and the study of sport. Hardcourt Publishers.

Ferrières, J., \& Ruidavets, J. B. (1999). Association between resting heart rate and hypertension treatment in a general population. American Journal of Hypertension, 12(6), 628-631. https://doi.org/10.1016/s0895-7061(99)00028-x

Hiilloskorpi, H. K., Pasanen, M. E., Fogelholm, M. G., Laukkanen, R. M., \& Mänttäri, A. T. (2003). Use of heart rate to predict energy expenditure from low to high activity levels. International Journal of Sports Medicine, 24(5), 332-326. https://doi.org/10.1055/s-2003-40701 
Hillman, C. H., Erickson, K. I., \& Kramer, A. F. (2008). Be smart, exercise your heart: Exercise effects on brain and cognition. Nature Reviews Neuroscience, 9, 58-65. https://doi.org/10.1038/nrn2298

Jebb, S. A., \& Moore, M. S. (1999). Contribution of a sedentary lifestyle and inactivity to the etiology of overweight and obesity: Current evidence and research issues. Medicine and Science in Sports and Exercise, 31(11 Suppl), S534-41. https://doi.org/10.1097/00005768-199911001-00008

McArdle, W., Katch, F. L., \& Katch, V. L. (2000). Essentials of exercise physiology (2nd ed.). Lippincott Williams and Wilkins.

Myers, J., Kaykha, A., George, S., Abella, J., Zaheer, N., Lear, S., Yamazaki, T., \& Froelicher, V. (2004). Fitness versus physical activity patterns in predicting mortality in men. American Journal of Medicine, 117(12), 912-918. https://doi.org/10.1016/j.amjmed.2004.06.047

Reimers, A. K., Knapp, G., \& Reimers, C. D. (2018). Effects of exercise on the resting heart rate: A Systematic review and meta-analysis of interventional studies. Journal of Clinical Medicine, 7(12): 503. https://doi.org/10.3390/jcm7120503

Rexhepi, A. M., \& Brestovci, B. (2014). Prediction of VO2max based on age, body mass, and resting heart rate. Human Movement, 15(1), 56-59. DOI: 10.2478/humo-2014-0003

Shephard, R. J., \& Shek, P. N. (1998). Immune responses to inflammation and trauma: A physical training model. Canadian Journal of Physiology and Pharmacology, 76(5), 469472. https://doi.org/10.1139/cjpp-76-5-469

Tanaka, H., Monahan, K. D., \& Seals, D. R. (2001). Age-predicted maximal heart rate revisited. Journal of the American College of Cardiology, 37(1), 153-156. https://doi.org/10.1016/s0735-1097(00)01054-8

Tremblay, M. S., Colley, R. C., Saunders, T. J., Healy, G. N., \& Owen, N. (2010). Physiological and health implications of a sedentary lifestyle. Applied Physiology, Nutrition, and Metabolism, 35(6), 725-740. https://doi.org/10.1139/h10-079

Troiano, R. P. Berrigan, D., Dodd, K. D., Masse, L. C., Tilert, T., \& McDowell, M. (2008). Physical activity in the United States measured by accelerometer. Medicine \& Science in Sports \& Exercise, 40(1), 181-1888. https://doi.org/10.1249/mss.0b013e31815a51b3

Uth, N., Sorensen, H., Overgaard, K., \& Pedersen, P. K. (2004). Estimation of VO2 max from the ratio between HRmax and HRrest - The Heart Rate Ratio Method. European Journal of Applied Physiology, 91(1), 111-115. https://doi.org/10.1007/s00421-003-0988-y

Warburton, D. E., Gledhill, N., \& Quinney A. (2001). Musculoskeletal fitness and health. Canadian Journal of Applied Physiology, 26(2), 217-237. https://doi.org/10.1139/h01-013

Winch, M. (2004). Strength training for athletes. Stanley L. Hunt Ltd.

Yasida, T., Brechue, W. F., Fujita, T., Shirakawa, J., Sato, Y., \& Abe, T. (2009). Muscle activation during low-intensity muscle contractions with restricted blood flow. Journal of Sports Sciences, 27(5), 479-489. https://doi.org/10.1080/02640410802626567 